\title{
TÉCNICAS EXPLORATÓRIAS NA PROSPECÇÃO DE KIMBERLITOS - ESTUDO DE CASO
}

\section{ROGÉRIO SILVESTRE PEREIRA ${ }^{1}$}

\begin{abstract}
RESUMO Em escala global, menos de 1\% dos kimberlitos podem ser considerados econômicos, e somente 15 pipes constituem minas de diamante de classe mundial. Até a década de 80 do século passado, exceto os depósitos aluvionares, os kimberlitos localizados nos Crátons arqueanos constituíam a única fonte viável de diamante. A descoberta em Argyle - Austrália de uma nova rocha (olivina lamproíto) com altos teores de diamante, redirecionou as pesquisas para um novo alvo, as faixas móveis que circundam os cratons arqueanos. A seleção da técnica mais apropriada em um programa de exploração para kimberlito e/ou lamproíto diamantífero baseia-se na disponibilidade de mapas geológicos adequados, fotografias aéreas, levantamentos geofísicos e no conhecimento da evolução geológica da área. A técnica de amostragem para recuperação de minerais indicadores é empregada em todo o mundo e vem sendo praticada desde que o kimberlito foi reconhecido em Kimberley, África do Sul, como a rocha fonte do diamante. Os resultados da técnica estão fundamentados nas análises geoquímicas dos minerais singenéticos ao diamante. A magnetometria aérea/terrestre constitui a segunda técnica mais usada na deteç̧ão direta de kimberlitos/lamproitos. Em Minas Gerais, essa técnica foi responsável pela identificação de centenas de kimberlitos e rochas relacionadas. A integração de dados sísmicos, gravimétricos e aeromagnéticos com geocronologia e geoquímica dos minerais indicadores podem proporcionar a definição de ambientes da litosfera favoríveis à preservação do diamante. Trabalhos desse tipo foram realizados na porção norte do Craton do São Francisco. A integração de imagens de satélite TM/radar com fotografias aéreas tem sido usada rotineiramente na identificação de feições relacionadas às intrusões de kimberlitos no Brasil. O sucesso do uso de fotografias aéreas na deteç̧ão direta de kimberlitos baseia-se principalmente no contraste da cobertura de vegetação entre a intrusão e a encaixante. A partir de 1997 , scanners multiespectrais passaram a ser usados na prospeç̧ão de kimberlitos. O equipamento opera no intervalo do espectro de ondas do SWIR, destacando anomalias $\mathrm{Mg}(\mathrm{OH})$. O artigo apresenta breve recapitulação sobre kimberlito, lamproito, gênese do diamante e revê as técnicas exploratórias mais usadas.
\end{abstract}

Palarras-chave: kimberlito, lamproíto, minerais kimberlíticos, núcleo arqueano, gravimetria, magnetometria, sensoriamento remoto, litosfera, geocronologia, diamante.

\begin{abstract}
EXPLORATORY TECHNIQUES IN KIMBERLITE EXPLORATION: CASE STUDY In a global scale, only 15 kimberlite pipes constitute world class diamond mines. Until the 1980's, except for the diamondiferous alluvial deposits, kimberlites located in the Archaen cratons were the only available dianond sources. The discovery of a new highly diamondiferous rock (olivine lamproite) in Argyle - Australia, re-directed the research for a new target, the mobile belts. The selection of appropriate techniques in a diamondiferous kimberlite/lamproite exploration program is based on the availability of suitable geological maps, aerial photographs, geophysical survey and knowledge of the area's geological evolution. The sampling technique for indicator minerals is used world wide and has been practicized since kimberlite was recognised in Kimberley - South Africa as the source rock of diamond. The technique results are based on geochemical data of diamond syngenetic minerals. The aerial and ground magnetometry constitute the second more used technique for direct detection of kimberlite/lamproite. Mainly in Minas Gerais State this technique was responsible for the identification of hundreds of kimberlites and related rocks. The integration of seismic, gravimetric, aeromagnetic, geochronological and geochemical data of indicator minerals can provide the definition of favorable lithosphere environment for the preservation of diamond. These types of research were developed in the northern portion of the São Francisco Craton. In Brazil, the integration of TM/radar satellite image with airphotographs has been routinely used to identify features related to kimberlite intrusions. The success of kimberlite direct identification using aerial photographs is based mainly on vegetation cover contrast between the intrusion and the country rocks. Since 1997, scanner multispectral technique has been used for kimberlite exploration. The equipment operates in the short wave infrared interval, enhancing $\mathrm{Mg}(\mathrm{OH})$ anomalies. The paper presents a brief overview about kimberlite, lamproite, genesis of diamond and a reviewing of the exploration techniques.
\end{abstract}

Keywords: kimberlite, lamproite, kimberlitic minerals, archean nucleous, gravimetry, magnetometry, remote sensing, lithosphere, geochronology, diamond.

INTRODUÇÃO Kimberlitos diamantíferos estão predominantemente confinados aos crátons antigos c estáveis no mundo. Em escala global, menos de $1 \%$ dos kimberlitos são suficientemente diamantíferos para serem considerados econômicos, e somente cerca de 15 pipes constituem minas de classe mundial. Os sucessos das descobertas dos últimos 35 anos, principalmente na Rússia (Mir, Udachnaya), Botswana (Orapa, Jwaneng), Austrália (Argyle) e no Canadá ( Lac de Gras Northwest Territories) na última década, refletem o êxito das aplicações de técnicas modernas, principalmente nas áreas de geofísica e geoquímica.

Exceto os depósitos aluvionares, os kimberlitos constituíam a única fonte econômica de diamante até a descoberta, em 1983, do lamproito Argyle (Western Australia). O alto teor de diamante na intrusão demonstrou a possibilidade de que um novo tipo de rocha (olivina lamproíto) também seria capaz de conter diamante. As áreas cratônicas antigas e estáveis, tidas até então como únicas na prospecção de diamante, foram consideravelmente ampliadas com a adição do novo ambiente geológico de Argyle, isto é, os cinturões móveis proterozóicos. Em todo o mundo, o novo alvo potencial para a prospecção de diamante passou a ser pesquisado. Kimberlitos, considerados historicamente como a maior fonte primária de diamantes, exibem propriedades físicas e químicas extremamente variá- 
veis. O reconhecimento de uma segunda fonte primária potencialmente econômica expandiu consideravelmente essas variáveis.

Aspectos de petrologia, mineralogia, geoquímica, geofísica, sensoriamento remoto e dados adicionais de campo, tais como variações da granulometria e cor do solo, anomalias específicas de determinadas espécies de vegetação e minerais identificados no bota-fora de formigueiros devem ser integrados aos programas de exploração. A seleção das técnicas mais apropriadas em um programa de exploração está baseada em fatores tais como a disponibilidade de fotografias aéreas/imagens e o tempo hábil em obtê-las, levantamentos geofísicos prévios, mapas adequados, facilidades de acesso e fisiografia do terreno, rocha encaixante, geomorfologia, nível de erosão na área alvo, idades das intrusões, espessura prevista de coberturas e, obviamente, disponibilidade de recursos para a execução do projeto. No Brasil a diversidade de clima, cobertura vegetal e vias de acesso da região amazônica para o nordeste e o sul do país, implica em estratégias diferentes no planejamento da prospeç̧ão, incluindo mesmo a adaptação das equipes de campo.

A técnica de amostragem de minerais pesados/indicadores é mundialmente empregada e praticada por mais de cem anos, desde que o kimberlito foi reconhecido em Kimberley na África do Sul como rocha fonte do diamante. No Brasil o follow up de minerais indicadores foi responsável pela descoberta de mais de uma centena de corpos kimberlíticos. Os resultados da técnica estão fundamentados nas análises visuais e químicas dos minerais singenéticos ao diamante nas paragêneses peridotítica e eclogítica. A quantidade de granada subcálcica, derivada de harzburgito, e o seu baixo teor em Ca podem assinalar o conteúdo de diamante. Cromita com alto teor de $\mathrm{Cr}_{2} \mathrm{O}_{3}$, níveis moderados a altos de $\mathrm{MgO}$ e muito baixo $\mathrm{TiO}_{2}$ tambem está associada ao diamante. A geoquímica dos minerais indicadores constitui, portanto, meio eficaz de avaliar o potencial para diamante dos alvos de exploração.

Em países de vasta extensão territorial como o Brasil, a redução das dimensões dos alvos regionais tem sido tentada por meio de modelos estruturais que apontam áreas mais favoráveis dentro de um contexto maior. Recentemente, a análise de produtos da integração dos dados de geofísica, sensoriamento remoto, geoquímica, geocronologia e geologia de superfície têm proporcionado mais consistência na seleção dos alvos. Apesar da ausência de dados sísmicos para o mapeamento de estruturas da litosfera, a integração de dados gravimétricos e magnéticos, geoquímica de minerais indicadores de kimberlitos, imagens de sistemas ótico/radar de satélite e geocronologia tem proporcionado sucesso na delimitação de blocos crustais/manto na porção norte do Craton do São Francisco. A presença de granada de alta pressão proveniente de kimberlitos situados na área mais central ou núcleo do Bloco Serrinha indica a presença de litosfera subjacente mais espessa, preservada do retrabalhamento durante o Ciclo Transamazônico.

Os dados de magnetometria aérea e terrestre têm sido usados com eficiência na deteç̧ão direta de corpos kimberlíticos e lampróíticos. Em áreas magneticamente muito agitadas, ou mesmo devido ao baixo magnetismo apresentado por alguns pipes (Argyle), o método deve ser usado com cautela. No Brasil, particularmente em Minas Gerais, o método aeromagnético foi responsável pela identificação de centenas de kimberlitos e rochas relacionadas.

$\mathrm{Na}$ área de sensoriamento remoto, imagens TM - Landsat e fotografias aéreas tem sido usadas. Devido à baixa resolução espacial e espectral das imagens para a detecção direta de kimberlitos ou lamproítos, essa técnica tem sido integrada com dados geofísicos para análises estruturais. Anomalias de vegetação constituem o principal critério na detecção direta de kimberlitos em fotografias aéreas. Essas anomalias são bem definidas e se relacionam com os solos férteis derivados das intrusões, sendo particularmente contrastantes se os solos originados das rochas encaixantes são arenosos. Associadas a outras técnicas, as fotografias aéreas tem sido usadas em análises estruturais, geomorfológicas, definição de vales e terraços de aluviões diamantíferos e principalmente na integração com dados de geofísica e imagens de satélite para identificação e follow up de anomalias. A partir de 1997, imageadores multiespectrais operando no intervalo de comprimento de ondas do SWIR (Short Wave Infrared) passaram a ser usados na prospecção de kimberlitos. Devido à alta resolução espacial e espectral, os sensores são capazes de detectar (pico de absorção) a hidroxila $\mathrm{Mg}(\mathrm{OH})$ de argilo-minerais típicos da alteração de kimberlitos. Levantamentos realizados no Brasil apontaram boas anomalias sobre kimberlitos conhecidos.

Por fim, o sucesso das técnicas exploratórias na prospecção de kimberlitos e lamproítos depende essencialmente do conhecimento e capacidade do geólogo de exploração em reconstruir a história da evolução geológica de uma região, proporcionando a seleção de alvos tão sólidos quanto possível. Depende ainda da tenacidade, perseverança, treinamento e aplicação das equipes de prospeç̧ão no campo.

Antes da revisão sobre as técnicas exploratórias usadas na prospeç̧ão de kimberlitos e lamproíto, apresentar-se-á uma recapitulação sobre essas rochas e a gênese do diamante.

KIMBERLITO Kimberlitos constituem variedades de rochas potássicas, volumetricamente insignificantes em escala mundial. Consistem de minerais, fragmentos de rochas e componentes magmáticos formados $\mathrm{em}$ ambientes físicos/químicos diversos, amostrados em diferentes profundidades pelo magma kimberlítico ao longo de sua ascensão desde o manto até a superfície.

A definição de kimberlito proposta por Clement et al. (1984), formalmente aceita até hoje, é de que este consiste de uma rocha ígnea ultrabásica, potássica, rica em voláteis, que ocorre em pipes vulcânicos, diques e sills. Possui textura inequigranular resultante da presença de fenocristais em matriz finamente granular. A olivina ocorre como fenocristal e constituinte da matriz, seguida de flogopita, calcita, serpentina, clinopiroxênio (comumente diopsídio), monticelita, apatita, espinélio, perovsquita e ilmenita. Os fenocristais são anédricos, derivados do manto, ferromagnesianos, e incluem olivina, flogopita, picroilmenita, espinélio cromífero, granada magnesiana, clinopiroxênio (comumente diopsídio cromífero) e ortopiroxênio (comumente enstatita). Os fenocristais e os minerais da matriz formados relativamente cedo são frequentemente alterados por processos deutéricos, principalmente serpentinização e carbonitização. Comumente contém inclusões de rochas ultramáficas, derivadas do manto superior, e quantidades variáveis de xenocristais e xenólitos crustais. Kimberlito pode conter diamante, porém como um constituinte raro. Geoquimicamente, são rochas ricas em $\mathrm{CO}_{2}, \mathrm{TiO}_{2}, \mathrm{~K}_{2} \mathrm{O}$, com componente volátil extremamente alto. Também sắo ricas em elementos traços incompatíveis tais como $\mathrm{Rb}, \mathrm{Sr}, \mathrm{Zr}, \mathrm{Nb}$, $\mathrm{Ba}, \mathrm{Cs}, \mathrm{Th}, \mathrm{U}, \mathrm{Pb}$ e Terras Raras Leves. 


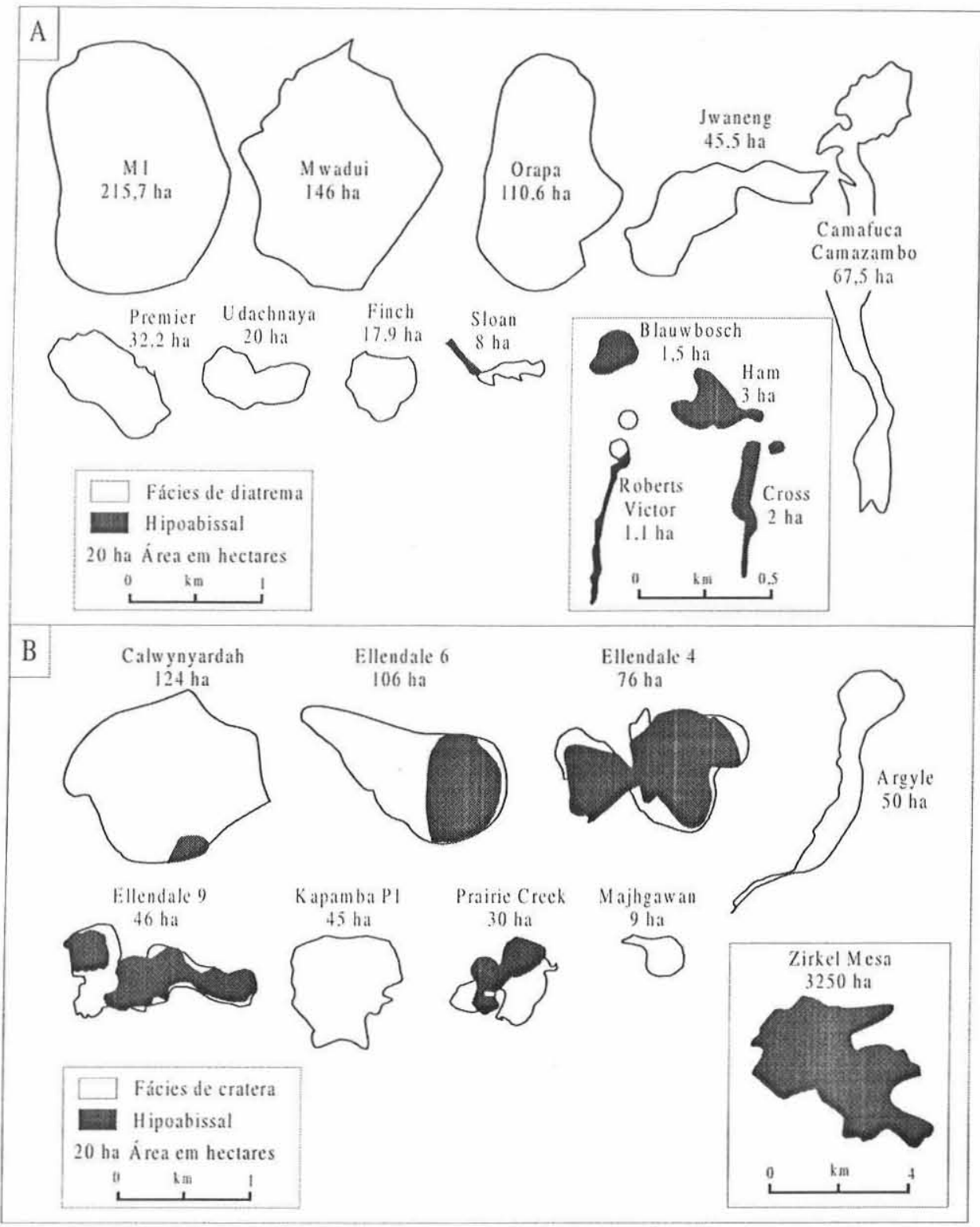

Figura 1 - Nível atual da erosão de diferentes intrusões. (A) - Kimberlitos (reproduzido de Scott-Smith 1992). (B) Lamproítos (reproduzido de Scott-Smith 1992).

A área de ocorrência de um kimberlito, que varia de alguns poucos hectares até mais de 200 hectares, reflete não somente a natureza da erupção, mas principalmente o nível da erosão da intrusão (Fig. 1). Intrusões do tipo pipe comumente contém 3 zonas distintas, isto é, a raiz, o diatrema e a cratera.

A zona da raiz apresenta formato irregular e contém rochas de vários pulsos de magmas com composições diferentes e texturas típicas de intrusões hipabissais Muitos dos kimberlitos hipabissais formados durante o desenvolvimento inicial do pipe podem não atingir a superfície (Clement 1982, Clement \& Reid 1989).

A zona do diatrema é a parte principal da intrusão. Ao contrário da zona da raiz, apresenta contatos regulares de mergulhos em ângulos altos com a rocha encaixante. Consiste de rochas com texturas incomuns que refletem a fluidização e a degasificação de sistemas intrusivos ricos em voláteis $\left(\mathrm{CO}_{2}\right)$. Lapilli pelletal são constituintes característicos destas rochas, onde a matriz é comumente cimentada por serpentina e micrólitos de clinopiroxênio.

A zona de cratera consiste na expressão superficial da intrusão. Constituída por material piroclástico primário, por vezes retrabalhado, a zona de cratera apresenta contatos de baixos mergulhos e mais irregulares quando comparados com a zona do diatrema.

Em pipes kimberlíticos, cada zona apresenta características diferentes na distribuição dos diamantes. Devido ao arranjo interno mais simples, a zona do diatrema mostra baixa flutuação dos teores, ao contrário da zona de raiz onde variam de acordo com as diferentes fases magmáticas. Na zona de cratera, os teores dependem dos resultados de interação dos processos piroclásticos primários com a erosão, re-sedimentação, intemperismo e lixiviação.

Teores economicamente viáveis de diamantes em kimberlitos variam de $\sim 3 c t s / 100 t$ a $>200 \mathrm{cts} / 100 \mathrm{t}$. A disparida- 
de entre os teores mais baixos e altos deve-se à avaliação (US\$/ ct) dos diamantes, que podem variar de US\$10/ct (Juina) até mais de US\$300/ct. As variações dos valores médios dos diamantes podem, portanto, inviabilizar economicamente kimberlito como o Monastery (Orange Free State) que apresenta, em algumas porções do pipe, teores de $50 \mathrm{cts} / 100 \mathrm{t}$ e viabilizar outros, como o kimberlito Letseng La Terae (Lesotho) com teores de $\sim 3 \mathrm{cts} / 100 \mathrm{t}$, mas que regularmente produz diamantes acima de 20cts do tipo gema.

Datações de kimberlitos e lamproítos indicam idades do Proterozóico ao Terciário. Tentativas de estabelecer uma ciclicidade de intrusões não tiveram êxito. Contudo, concentrações maiores em determinados intervalos de tempo podem ser observadas, como por exemplo, entre o Jurássico Inferior (175Ma - 190Ma) e o Cretáceo Superior (65Ma - 80Ma). No Brasil, a maioria dos kimberlitos se concentra entre $80 \mathrm{Ma}-$ 125Ma.

Kimberlitos estão restritos a ambiente de intraplaca continental, mais especificamente às regiões da crosta continental sobrejacente a crátons mais velhos que $2,5 \mathrm{Ga}$. A localização de 95\% das minas de diamantes nesse ambiente reforça as observações de Clifford (1966) e Dawson (1980) de que kimberlitos economicamente importantes estão confinados a núcleos cratônicos arqueanos.

\section{LAMPROÍTOS A descoberta de lamproíto diamantífero} despertou grande interesse. Estudos sobre o mesmo foram realizados por Scott-Smith \& Skinner (1984), Mitchell (1989), Mitchell \& Bergman (1991) e Scott-Smith (1992). Lamproíto é uma rocha ígnea magnesiana, ultrapotássica e se caracteriza pela alta razão $\mathrm{K}_{2} \mathrm{O} / \mathrm{Na}_{2} \mathrm{O}$ e concentrações elevadas de $\mathrm{Cr}$, $\mathrm{Ni}$, $\mathrm{Rb}, \mathrm{Sr}, \mathrm{Zr}$, e Ba. Ao contrário do kimberlito, o $\mathrm{CO}_{2}$ é praticamente ausente. Contem quantidades variáveis de leucita como fenocristal primário ou constituinte da matriz. Outros minerais proeminentes são flogopita titanífera, clinopiroxênio (tipicamente diopsídio), richterita titanífera potássica, olivina $\mathrm{c}$ sanidina. Priderita, perovsquita, apatita, wadeita e espinélio podem ocorrer. A distinção entre lamproito e kimberlito é feita pela presença, no primeiro, de leucita, anfibólio, sanidina, vidro, priderita, wadeita e ausências de monticelita, carbonato e serpentina primários.

Em contraste com kimberlitos, que atingem profundidades de $2 \mathrm{~km}$, os lamproitos não ultrapassam $500 \mathrm{~m}$, o que resulta na ausência da zona de diatrema e de zona de raiz menos desenvolvida que nos kimberlitos. O pouco desenvolvimento dessas zonas é atribuído à baixa presença de $\mathrm{CO}_{2}$ na erupção dos magmas lamproíticos, resultando em maior participação da zona de cratera, acompanhada de pequenos vents ou alimentadores, exibindo o conjunto um formato de taça de champagne, ao contrário do formato em cone dos kimberlitos. Uma característica muito própria do lamproíto consiste na intrusão de magma tardio no depósito piroclástico, usualmente na forma de lagos de lava.

Lamproítos, como os kimberlitos, são produtos de magmatismo intraplaca. Contudo, ao contrário dos kimberlitos (econômicos) que estão confinados aos cratons arqueanos, os lamproítos geralmente ocorrem nas margens dos cratons, junto aos cinturões móveis.

As diversidades do ambiente tectônico, tipo de emplacement, formato do corpo e diferente mineralogia obviamente têm implicações na seleção dos alvos, técnicas exploratórias e determinação dos teores em diamante entre lamproítos e kimberlitos.

GÊNESE DO DIAMANTE Os kimberlitos diamantíferos estão confinados às áreas cratônicas arqueanas. As relações entre anomalias de alta velocidade das ondas S (shear wave) e a espessura da litosfera permitem estimar nestas áreas a espessura média da litosfera pós-arqueana entre 100 e $200 \mathrm{~km}$, podendo alcançar mais de $300 \mathrm{~km}$.

Datações $\mathrm{Sm} / \mathrm{Nd}$ de ortopiroxênio, granada encapsulada em diamantes e Re-Os de xenólitos da litosfera de kimberlitos da África do Sul e Sibéria, indicam que os crátons arqueanos e as litosferas mais espessas subjacentes foram formados no Arqueano (Condie 1997).

Provavelmente devido ao empobrecimento de elementos radiogênicos como $\mathrm{U}$ e $\mathrm{Th}$, as áreas arqueanas apresentam fluxo térmico menor que as mais jovens. A inflexão das geotermas para a base de litosferas subjacentes à cratons arqueanos indica que as temperaturas são menores que as observadas na mesma profundidade, porem fora desse ambiente (Haggerty 1986). A convergência dos dados permite indicar que os diamantes são formados, e permanecem estáveis, na raiz "fria" e menos densa das quilhas litosféricas sob os cratons arqueanos, onde a estabilidade do mineral é limitada por temperaturas entre $900^{\circ} \mathrm{e} 1300^{\circ} \mathrm{C}$, profundidades de 150 a $200 \mathrm{~km}$, pressões entre 45 e $65 \mathrm{kba}$ e geoterma próximo a $40 \mathrm{mWm}^{-2}$.

Estudos de inclusões de minerais em diamantes e da assembléia de minerais em xenólitos diamantíferos mostram que a formação dos diamantes na base da litosfera está associada a 2 tipos de rochas: granada peridotito, com predominância de granada harzburgito sobre o lherzolito, e eclogito. A composição química dessas inclusões indica fonte situada no manto superior, constituída por granada harsburgito com lentes de eclogito, empobrecida em FeO, $\mathrm{Al}_{2} \mathrm{O}_{3}, \mathrm{CaO}$ (Nyblade 2001) e enriquecida em LREE por metassomatismo.

Diamantes peridotíticos (tipo P) e eclogíticos (tipo E) constituem populações distintas. Datações de diamantes do tipo $\mathrm{P}$ provenientes de kimberlitos da África do Sul e Sibéria indicam que estes são arqueanos. Por outro lado, diamantes do tipo $\mathrm{E}$ recuperados de eclogitos diamantíferos (Roberts Victor, Áfirica do Sul) mostram idades entre $2.7 \mathrm{Ga}$ e $990 \mathrm{Ma}$. A presença de diamantes de idades diferentes em um mesmo kimberlito, como na mina Finsch (África do Sul), implica em processos distintos de formação dos tipos P e E. Ambos tipos também diferem na composição isotópica de carbono $\left(\delta^{13} \mathrm{C}\right)$, uma vez que nos do tipo $\mathrm{P}$ os valores estão confinados entre -2 e -9 per mil, semelhantes aos obtidos em substâncias derivadas do manto, enquanto os do tipo E apresentam valores entre $-34 \mathrm{e}+3$ per mil, semelhantes aos observados em materiais da crosta. Os valores distintos nos dois tipos sugerem que a fonte de carbono dos diamantes peridotíticos é astenosférico e dos eclogíticos é crustal, reciclada para o manto por subducção.

Os diamantes formados no Arqueano e/ou Proterozóico permanecem estáveis na base da litosfera por longo período de tempo até a sua captura por kimberlitos/lamproítos muito mais jovens (preferencialmente paleozóicos e mesozóicos). O transporte do diamante desde seu campo de estabilidade até a superfície implica em grande diluição do teor, indicando um meio física e quimicamente hostil que resulta em absorções, quebra e abrasão dos cristais (Fig. 2). As feições de absorção mostram que os diamantes não estão em equilíbrio com o magma kimberlítico, e são submetidos à oxidação durante o transporte. 
Em termos de exploração, os fatores mais importantes na gênese do diamante podem ser resumidos aos seguintes pontos:

Os macrodiamantes presentes em depósitos econômicos derivam de rochas fontes peridotíticas e eclogíticas e constituem xenocristais em kimberlitos e lamproítos .

- A abundância de inclusões de minerais peridotíticos indica que os do tipo P são mais abundantes que os do tipo E. Entretanto, em relação aos xenólitos observa-se o inverso, sugerindo uma desagregação maior de peridotito diamantífero.

- Ambas as paragêneses do diamante são mais antigas que as rochas transportes/hospedeiras.

- Diamantes peridotíticos são formados em peridotito quimicamente empobrecido $\left(\mathrm{FeO}, \mathrm{Al}_{2} \mathrm{O}_{3}, \mathrm{CaO}\right)$ na base da litosfera $(150-200 \mathrm{~km})$, onde são enriquecidos em LREE, K e Rb, por meio de evento metassomático pobre em Ti.

- No caso de microdiamantes associados ao magma hospedeiro, seu conteúdo no kimberlito e lamproíto pode não estar relacionado aos macrodiamantes da mesma intrusão.

Os diamantes são encontrados preferencialmente em regiões onde as rochas antigas são preservadas e mostram uma quilha litosférica espessa e fria em subsuperfície.

O transporte do diamante do manto até a superfície necessita ser rápido para evitar a destruição do mineral.

TÉCNICAS EXPLORATÓRIAS Durante aproximadamente 100 anos, as técnicas de exploração foram desenvolvidas com o objetivo de localizar kimberlitos. A partir da década de 80 do século passado, a descoberta da rocha com alto teor de diamante no noroeste da Austrália, exigiu das empresas uma reorientação das pesquisas para o novo alvo.
$\mathrm{O}$ ambiente geotectônico, aliado à presença menor dos minerais indicadores da nova fonte diamantífera primária, contribuíram para a revisão da tradicional técnica exploratória de amostragem para minerais indicadores, em especial quanto ao volume da amostra. Devido às pequenas proporções de granada, espinélio, diopsídio e ilmenita, abundantes no kimberlito típico, o olivina lamproíto de Argyle foi descoberto por meio do follow up de diamante, cujos teores são excepcionalmente altos.

Atualmente, as técnicas exploratórias consistem mais e mais na integração dos dados obtidos pelos diferentes métodos. Os alvos definidos para levantamentos acromagnéticos, de fotografias aéreas ou scanner multiespectral, invariavelmente são resultados da integração de amostragens positivas de minerais com modelos estruturais, embasados em interpretações de imagens ótica/radar de satélite e mapas geológicos disponíveis. Por outro lado, amostragens detalhadas ou follow up de minerais são planejados seguindo mapas, cujos dados são originados da integração das anomalias selecionadas nos diferentes tipos de aerolevantamentos com resultados mineralógicos, interpretações geológico/estruturais e geomorfológicas detalhadas.

As correlações de dados geoquímicos de minerais singenéticos ao diamante nas paragêneses peridotítica e eclogítica, com dados de sísmica profunda, magnetometria, gravimetria, geocronologia e geologia de superfície, podem indicar a presença de litosfera mais espessa, favorável à preservação do diamante. Nesse aspecto, foram desenvolvidos trabaIhos com êxito na porção norte do Craton do São Francisco.

Entre as técnicas exploratórias mais usadas mundialmente na prospecção de kimberlitos e lamproítos destacam-se a amostragem para recuperação de minerais pesados/indicado-
Octaedro

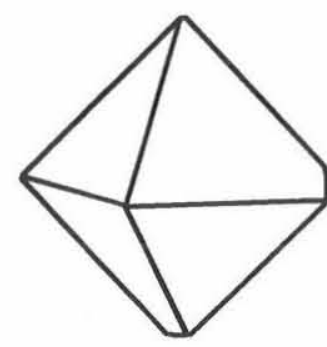

Forma de crescimento
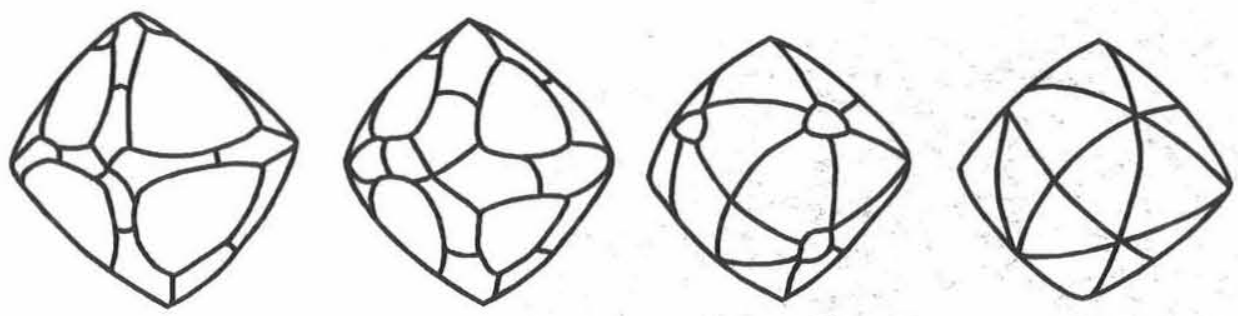

Reabsorção
Tetrahexaedróide

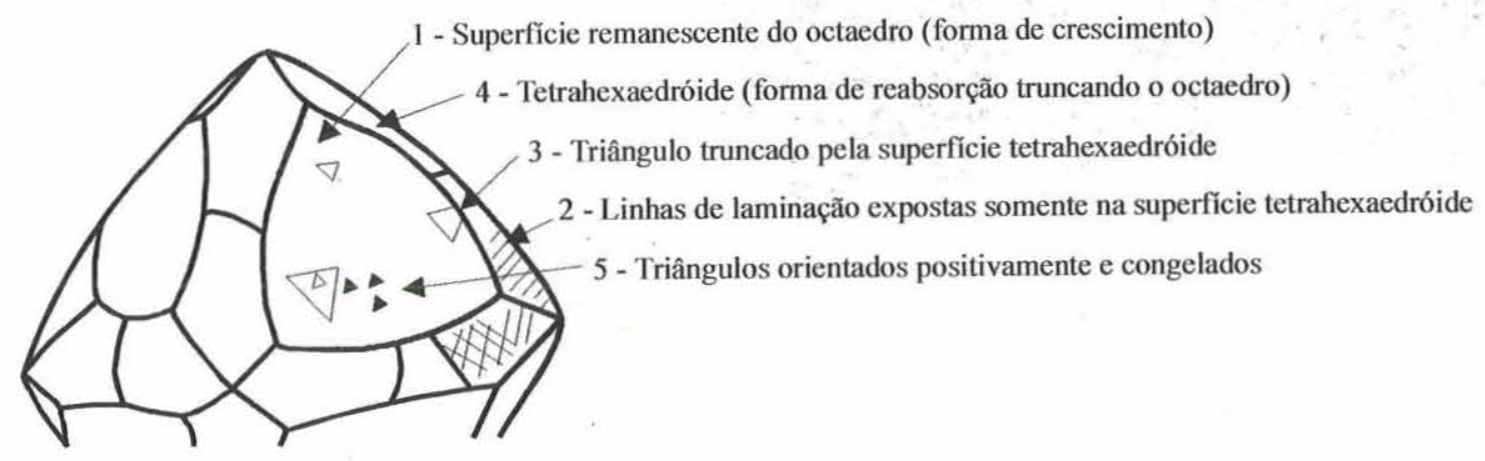

Figura 2 - Feições de reabsorção de diamante 
res, a geofísica aérea/terrestre e o sensoriamento remoto. Outras técnicas menos usadas, porém ainda aplicadas, são a amostragem geoquímica e a geobotânica, esta última observada com frequência em fotografias aéreas. A associação de anomalias geoquímicas de solo $(\mathrm{Ni}, \mathrm{Cr}, \mathrm{Nb}, \mathrm{Mg})$ com a intrusão diamantífera de Dachine na Guiana Francesa e a disponibilidade de extensos blocos de amostragens, bem como levantamentos aeromagnéticos de boa qualidade permitiram o uso da técnica de amostragem geoquímica na seleção de alvos para kimberlito/lamproito nesse país.

Amostragem para minerais pesados/indicadores A técnica de amostragem para recuperação de granada, espinélio, diopsídio e ilmenita constitui a base da prospecção para kimberlito e lamproito (Fig. 3). O método, desenvolvido especificamente para ocorrências de kimberlitos na África do Sul, tem sido aplicado com sucesso em todo o mundo. $\mathrm{Na}$ amostragem, incluem-se sedimentos de corrente, solos, tilitos e conglomerados. A densidade e o volume das amostras variam de acordo com as fases de reconhecimento, intensificação, follow up e ambientes mais ou menos concentradores de minerais pesados. A morfologia da superfície dos grãos, tais como grau de abrasão (arestas mais ou menos vivas dos minerais), arredondamento e a proporção maior ou menor da capa que envolve o mineral (superfície kelifítica em granadas), pode ser usada para estimar a distância da fonte primária. Descrições das técnicas de recuperação/separação dos minerais, desde o peneiramento em diferentes granulometrias até o concentrado final obtido em laboratório não cabem nesse trabalho.

A contribuição maior dos minerais indicadores está no acesso ao potencial diamantífero da fonte, definida pela interpretação das composições químicas dos minerais. Cabe frisar que o

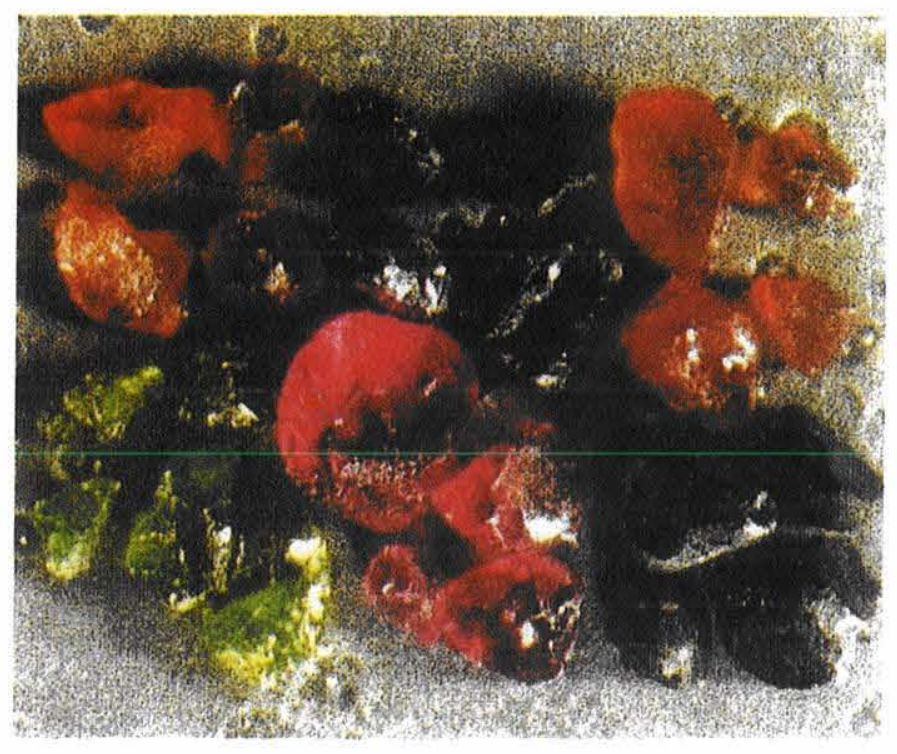

Figura 3 - Minerais pesados/indicadores. Fotomicrografia (25x) de minerais provenientes de tilito, coletados a jusante do kimberlito Point Lake, NWT-Canadá. Observa-se a partir do canto superior esquerdo em grupos de 4: granadas eclogíticas, picroilmenitas, megacristais de granadas eclogíticas, $\mathrm{Cr}$ diopsídios, granadas peridotíticas (GIO), $\mathrm{Ti}-\mathrm{Cr}$. cromitas (Fipke et al. 1995). sucesso do método desenvolvido para os minerais se aplica a kimberlitos, e com algumas modificações a lamproítos.

USO DE GRANADA Na paragênese do diamante peridotítico, três subgrupos de rochas são reconhecidos como fontes potenciais de diamantes: granada harzburgito, cromita harzburgito e granada therzolito. Em razão de que $85 \%$ das inclusões de granadas em diamantes são do tipo granada subcálcica, típica do harsburgito, o potencial diamantífero deriva da maior ou menor quantidade deste mineral na rocha. $\mathrm{O}$ diagrama $\mathrm{Cr}_{2} \mathrm{O}_{3}-\mathrm{CaO}$ (Fig. 4) para granadas peridotíticas inclusas em diamantes provenientes de várias localidades do mundo, mostra que $85 \%$ (G10) caem no campo mais pobre $\mathrm{em}$ $\mathrm{CaO}$ quando comparadas com as granadas (G9). Na prática, granadas therzolíticas de alta pressão podem situar-se no campo das subcálcicas, ou o inverso para pressões mais baixas. Contudo, empiricamente nota-se que a maioria das granadas peridotíticas de kimberlitos diamantíferos situam-se sempre no campo das variedades subcálcicas.

USO DA CROMITA A cromita é usada de maneira similar à granada na indicação do potencial diamantífero dos diatremas derivados de harzburgitos (Fig. 5). Cromita associada a diamante mostra alto teor de $\mathrm{Cr}\left(>60 \%\right.$ wt $\left.\% \mathrm{Cr}_{2} \mathrm{O}_{3}\right) \mathrm{c}$ moderado a alto teor de $\mathrm{Mg}(\sim 12$ a $16 \mathrm{wt} \% \mathrm{MgO})$. Teores muito baixos de $\mathrm{TiO}_{2}(<0,3 \mathrm{wt} \%$, raramente $>0,6 \mathrm{wt} \%)$ tambem é uma característica. O conteúdo de $\mathrm{Cr}$ na cromita constitui o indicador crítico do potencial diamantífero da fonte.

Na paragênese eclogítica, os estudos de xenólitos mostram que determinada variedade de eclogito contém granada e clinopiroxênio anômalos em Na e K respectivamente (Fig. 6). Diamantes estão sempre associados a esse grupo de eclogito, c o parâmetro químico diagnóstico do potencial diamantífero está relacionado ao teor de Na na granada.

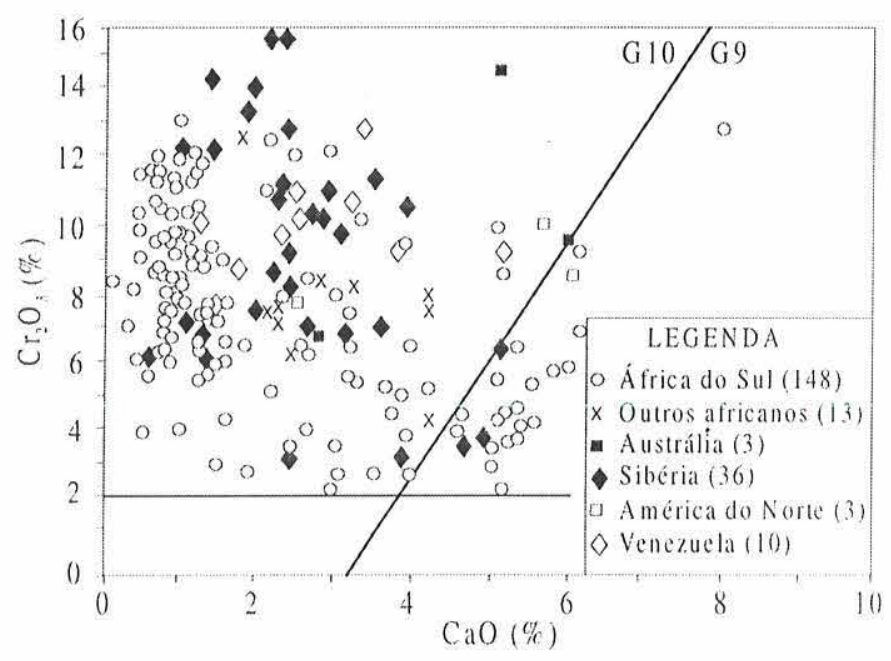

Figura 4-Diagrama $\mathrm{Cr}_{2} \mathrm{O}_{3}-\mathrm{CaO}$ de inclusões de granada peridotítica em diamante. Oitenta e cinco porcento das granadas situam-se no campo mais pobre em $\mathrm{CaO}$, definido pela linha inclinada estabelecida por Gurney em 1984. As composições subcálcicas referem-se às granadas G10. A linha horizontal de $2 \%$ de $\mathrm{Cr}_{2} \mathrm{O}_{3}$ é usada como divisão arbitrária entre granada eclogítica, abaixo da linha e granada peridotítica acima (Fipke et al. 1995). 
Apesar de não ser infalível, o uso da geoquímica dos minerais indicadores é relevante na avaliação de kimberlitos conhecidos. A técnica tem sido aplicada com sucesso em Botswana, Venezuela (Guaniamo), África do Sul, Guiné e recentemente na importante descoberta de Lac de Gras - Northwest Territories, Canadá. No Brasil, mesmo kimberlitos levemente diamantíferos sempre são ricos em granada subcálcica e espinélio de alto interesse. Em geral, alvos que apresentam granada subcálcica, cromita com alto $\mathrm{Cr}$, populações de granada eclogítica com alto $\mathrm{Na}$ e ilmenita magnesiana devem ser considerados como de alta prioridade.

O sucesso da técnica em relação aos kimberlitos aplica-se parcialmente aos lamproítos. A razão para isto reside nas populações menores dos minerais indicadores nesse tipo de rocha. Em Argyle, $32 \mathrm{~kg}$ de tufo arenoso com alto teor de diamante indicou somente 3 grãos de granada peridotítica e 3 eclogíticas. Resultado semelhante também foi observado no lamproíto de Prairie Creek (Arkansas, USA), onde $42 \mathrm{~kg}$ da facies mais diamantífera forneceu 2 granadas eclogíticas e 3 peridotíticas (Fipke et al. 1995). Assim, o volume da amostra na prospecção para lamproíto é fundamental. Argyle, responsável por $1 / 3$ da produção mundial de diamante, foi descoberto por meio de 3 amostras de $40 \mathrm{~kg}$ de aluvião, coletadas em intervalos de $5 \mathrm{~km}$ a jusante da intrusão, das quais foram recuperados 2, 4, e 5 diamantes respectivamentes (Jaques et al., 1986). Volumes inferiores de amostragens obviamente não recuperariam minerais e provavelmente também não diamantes.

No Brasil, após o impacto da descoberta de Argyle, as considerações e implementações mais importantes adotadas foram quanto à adição das novas áreas potencialmente favoráveis à prospeç̧ão. Poucas alterações foram introduzidas com respeito à amostragem.

Geofísica A magnetometria aérea/terrestre pode ser considerada como a segunda técnica mundialmente mais usada na detecção direta de kimberlitos. A eficiência da técnica depende da intensidade magnética do corpo em relação à rocha encaixante. A detecção de um kimberlito e/ou lamproíto é portanto facilitada quando a rocha encaixante é pouco condutiva, favorecendo o contraste entre intrusão/encaixante. Em consequência, a técnica deve ser usada com cautela em áreas magneticamente muito agitadas ou quando os kimberlitos conhecidos na região são poucos magnéticos. Principalmente em Minas Gerais, o método foi responsável pela identificação direta de centenas de kimberlitos e rochas relacionadas, intrusivas em quartzitos, xistos, calcários e siltitos. Contrastes particularmente notáveis (anomalias dipolares) são obscrvados quando as encaixantes são quartzitos, arenitos e calcários. Com o objetivo de estabelecer prioridades das anomalias ou facilitar a navegação no campo, os dados aeromagnéticos são integrados com imagens de satélite e fotografias aéreas (Fig. 7).

No Brasil e em outros países, o uso da magnetometria terrestre está limitado ao levantamento de pequenas áreas, comumente na avaliação de anomalias aeromagnéticas, de folografias aéreas e espectrais (AMS). Nos levantamentos aeromagnéticos para detecção de kimberlitos a altura de vôo varia de 80 a $100 \mathrm{~m}$, com espaçamento entre linhas de $300 \mathrm{~m}$, $250 \mathrm{~m}$ e $125 \mathrm{~m}$, com $\sim 7$ leituras/seg. As linhas de controle situam-se a intervalos de $2500 \mathrm{~m}$. O custo de um levantamento com volume $\sim 40.000 \mathrm{~km} /$ linha situa-se, no Brasil, em torno de US\$10/km e em levantamentos com gradiômetro (3 sensores) US\$13/km.

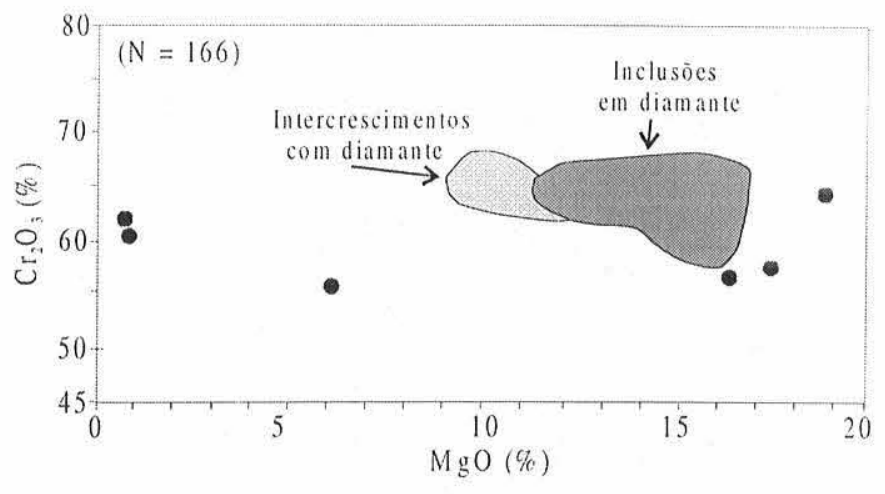

Figura 5 - Inclusões de cromita em diamante. Diagrama $\mathrm{Cr}_{2} \mathrm{O}_{3}-\mathrm{MgO}$ de inclusões e intercrescimentos de cromitas em. diamantes de 166 amostras provenientes da África do Sul (140), Sibéria (18), Austrália (1) e outras localidades (6). Observe-se a composição restrita das inclusões e intercrescimentos, exceto algumas amostras que não coincidem com os campo. (modificado de Fipke et al. 1995).

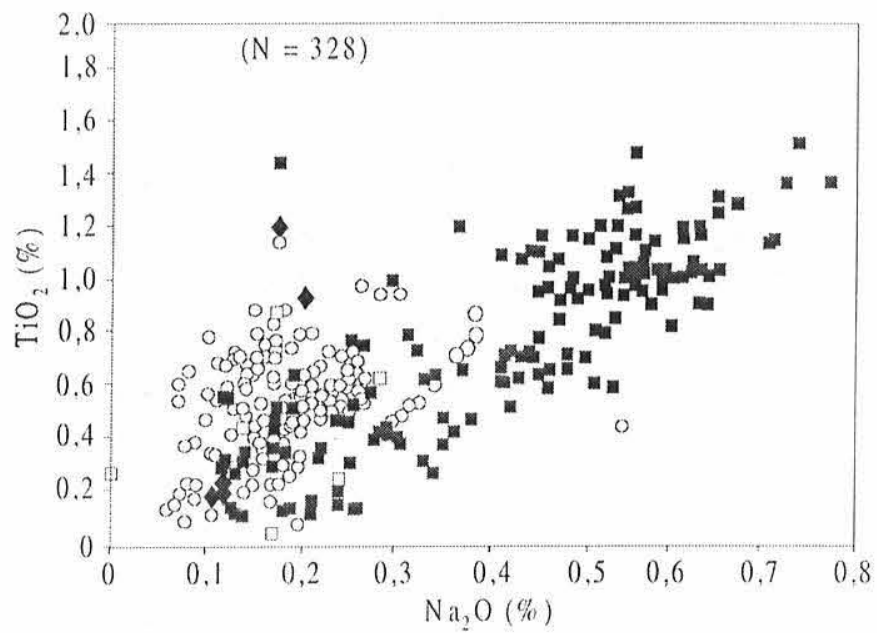

Figura 6 - Inclusões de granada eclogítica. Diagrama $\mathrm{TiO}_{2}-$ $\mathrm{Na}_{2} \mathrm{O}$ para inclusões de granada em diamantes eclogíticos de diferentes localidades do mundo. Granadas com $\mathrm{Na}_{2} \mathrm{O}>$ $0,07 \%$ são consideradas significativas na avaliação do potencial diamantífero da intrusão. Os dados das inclusões no diagrama consistem: África do Sul (140), Austrália (134), Sibéria (9), América do Norte (36). Símbolos como da Fig. 4 (modificado de Fipke et al. 1995).

Um outro aspecto importante do uso da geofísica na prospecção de kimberlitos tem sido a sua capacidade de delinear blocos crustais/manto por meio de dados sísmicos, gravimétricos e magnéticos, que, associados à geocronologia e geoquímica dos minerais kimberlíticos podem definir ambientes da litosfera favoráveis à preservação de diamante. A delineação de domínios do manto sob o ponto de vista estritamente geofísico só é possível com a telesísmica (O’Reilly, 1996). Contudo, faz sentido geológico a assertiva de que domínios cratônicos crustais delimitados pela gravimetrial magnetometria e consubstanciados por dados geoquímicos de 


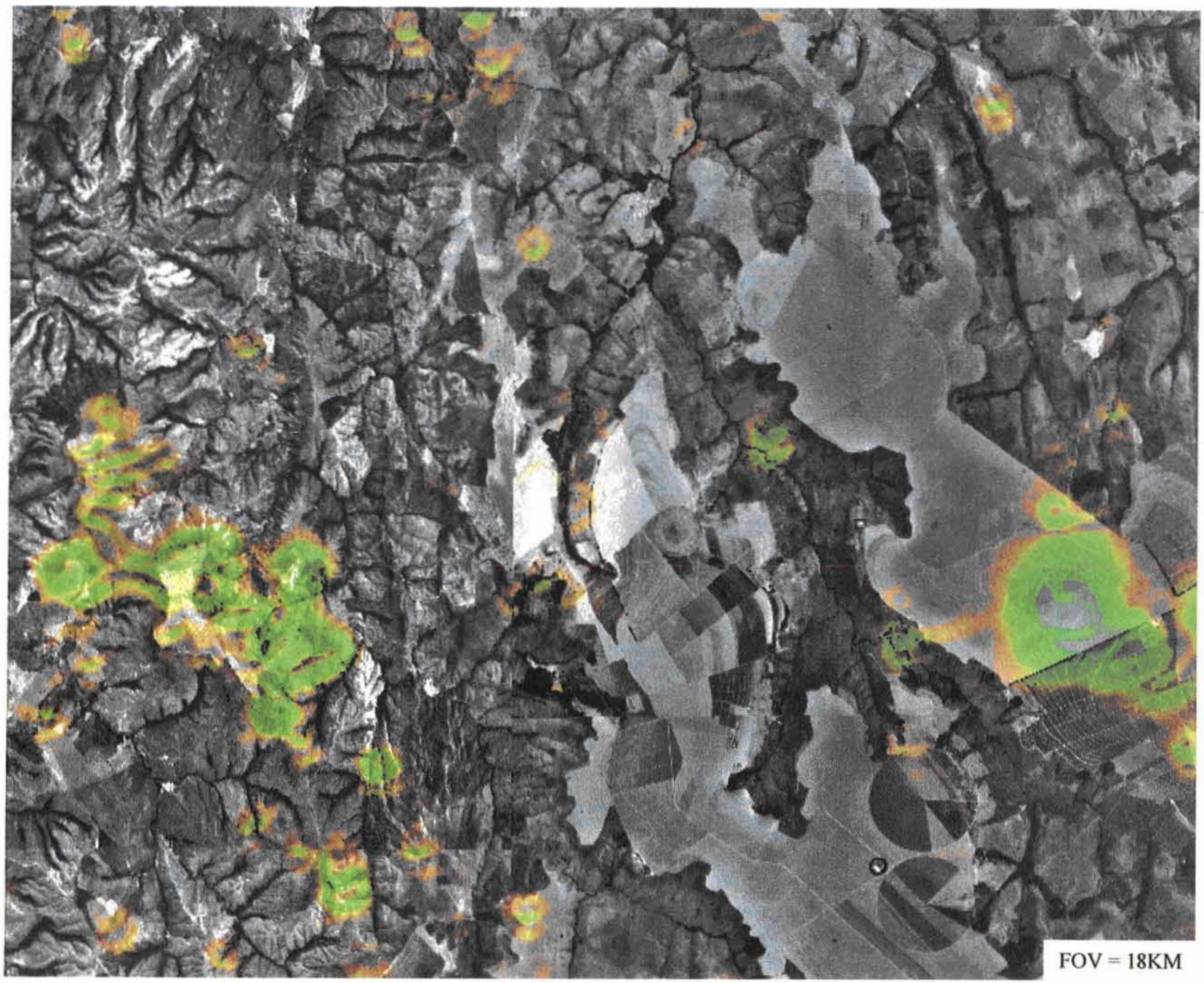

Figura 7 - Anomalias aeromagnéticas de kimberlitos sob cobertura sedimentar terciária. Composição: fotografia aérea + sinal analítico. Fonte dos dados: De Beers do Brasil.

minerais kimberlíticos podem representar, por extensão, domínios de manto.

A interpretação dos dados gravimétricos (South American Gravity Project) e aeromagnetométricos (South American Magnetic Mapping Project) permitiu delinear domínios discretos na porção norte do Craton do São Francisco (Fig. 8A). A integração desses domínios com dados de química mineral, geocronologia e geologia de superfície obtida de imagens de satélite, permitiu, por sua vez, discriminar blocos crustais/manto de idades arqueanas correspondentes ao Complexo Jequié e Bloco Serrinha (Fig. 8B). Análises de granadas e clinopiroxênios de kimberlitos das várias províncias do Bloco Serrinha indicam que o manto da região apresentava temperaturas entre $950^{\circ}$ e $1200^{\circ} \mathrm{C}$ e pressões entre 34,5 kbar e $55 \mathrm{kbar}$ (Edler \& Bizzi, 1996). Considerando as granadas de pressão mais alta e os dados correspondentes de clinopiroxênios para cada província kimberlítica, o gradiente geotérmico situava-se entre $42 \mathrm{mWm}^{-2}$ e $45 \mathrm{mWm}^{-2}$, respectivamente para a porção central e bordas do bloco, estimativas que são consistentes com os resultados de termometria calculados com base no teor de Ni em granada (Fig. 9). Esta variação indica uma litosfera mais espessa no centro, que se adelgaça em direção às margens retrabalhadas pelas orogêneses proterozóicas. A integração dos dados sugere que o Bloco Serrinha apresenta um núcleo pouco afetado pelo retrabalhamento durante o Ciclo Transamazônico e cuja quilha litosférica mostra ambiente favorável à preservação de diamante (Pereira et al. 1996). Alvos assim definidos constituem os terrenos clássicos para a prospecção de kimberlitos diamantíferos.

Sensoriamento Remoto A integração de imagens de satélite TM/radar, geofísica e fotografias aéreas tem sido usada rotineiramente na identificação de feições relacionadas às intrusões de kimberlitos no Brasil (Fig. 10). A vantagem da integração dos dados de diferentes sistemas está em compor uma única imagem com os ganhos individuais de cada sistema.

A experiência na interpretação de fotografias aéreas, imagens de satélite e radar indica que as feições de superfície relacionadas às intrusões estão intimamente ligadas ao uso da terra, ambiente geológico e pedogênese. Aspectos tais como tipo da rocha encaixante, vegetação, clima, história da erosão e tamanho da intrusão são relevantes. A importância do uso da 

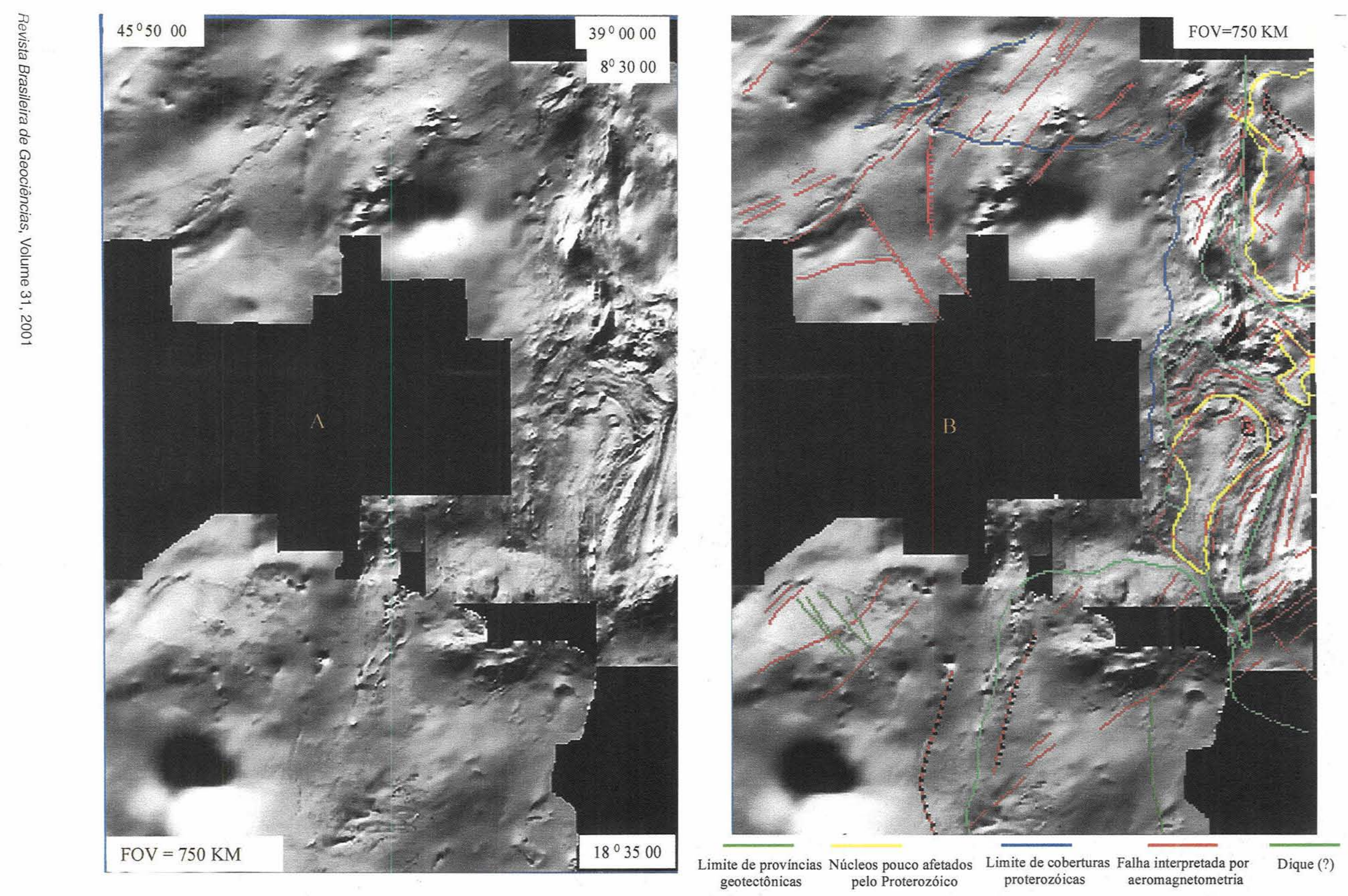

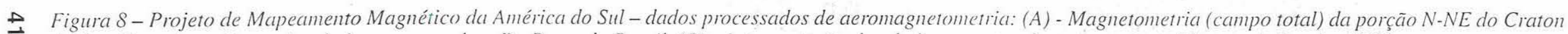
$\vec{\omega}$ do São Francisco. Fonte dos dados processados: De Beers do Brasil. (B) - Interpretação dos dados processados campo magnético total. Pereira 1996. 


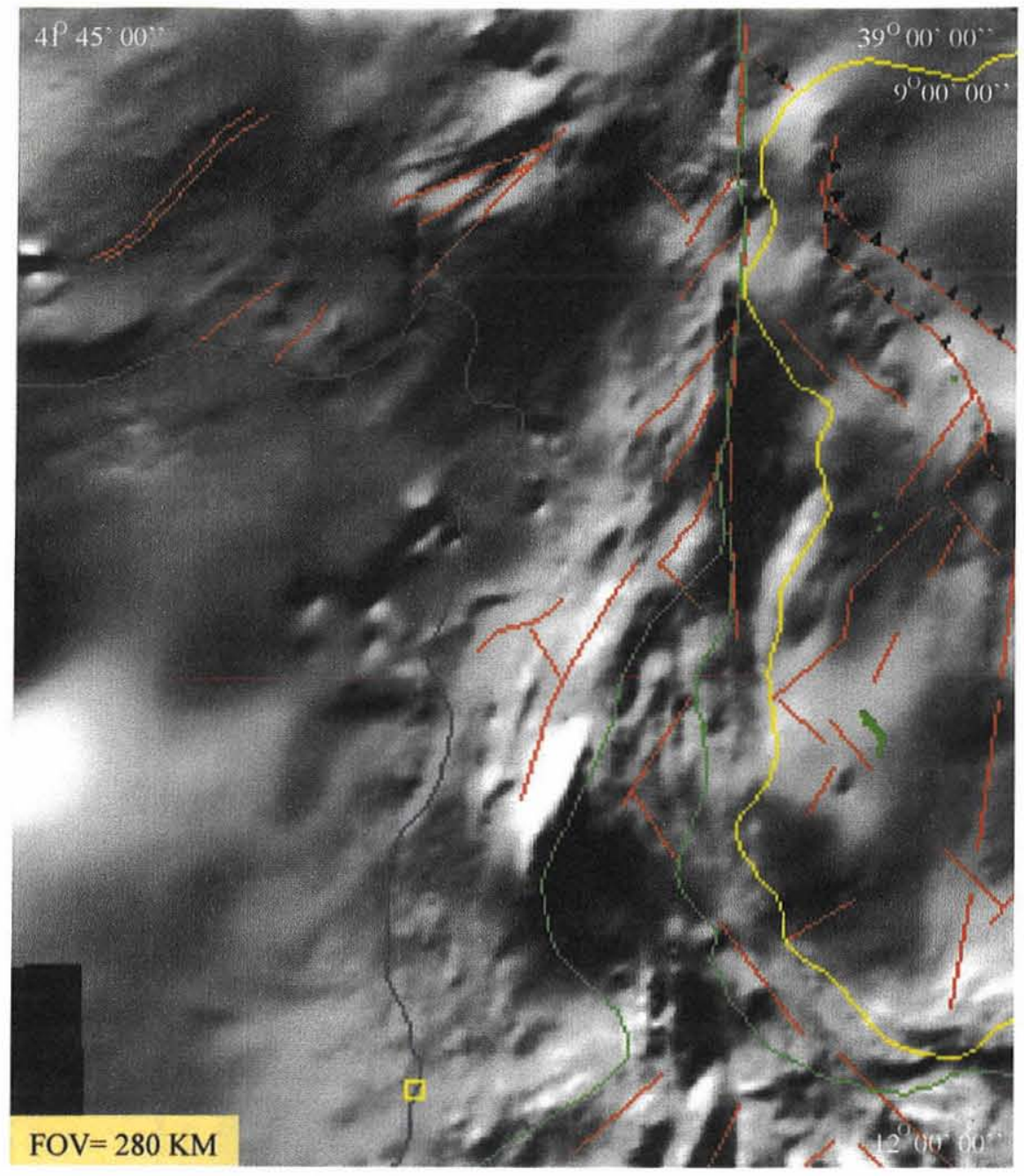

A

LEGENDA

Limite de províncias geotectônicas

Limite do Bloco Serrinha pouco afetado pelas orogêneses proterozóicas

Limite de coberturas proterozóicas

Falhas intepretadas por dados magnéticos [1]

Ponto com rochas de idade entre $2.5 \mathrm{Ga}$ e $3.0 \mathrm{Ga}$

-

Kimberlitos

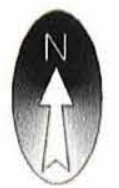

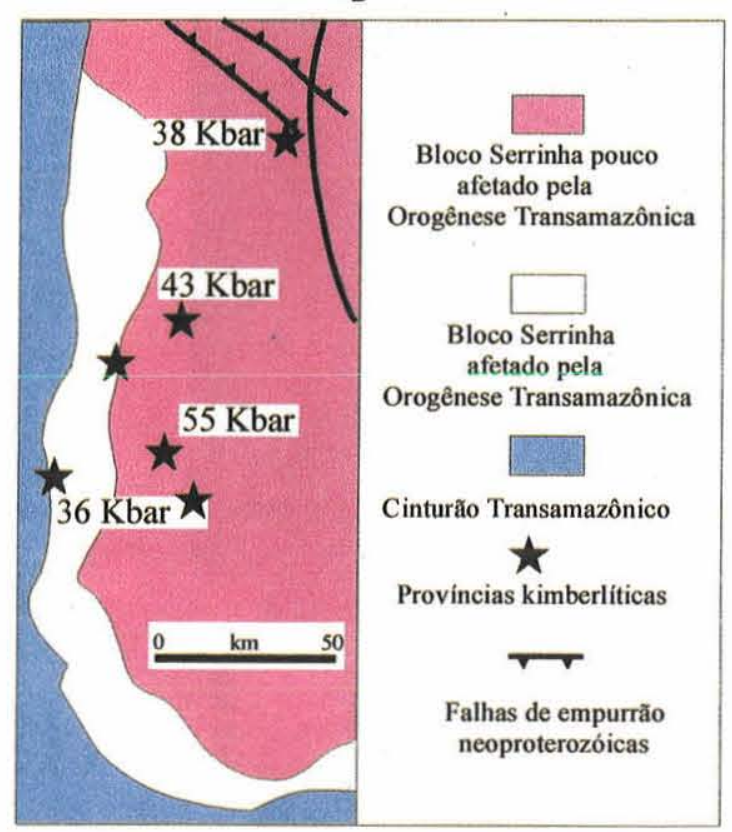

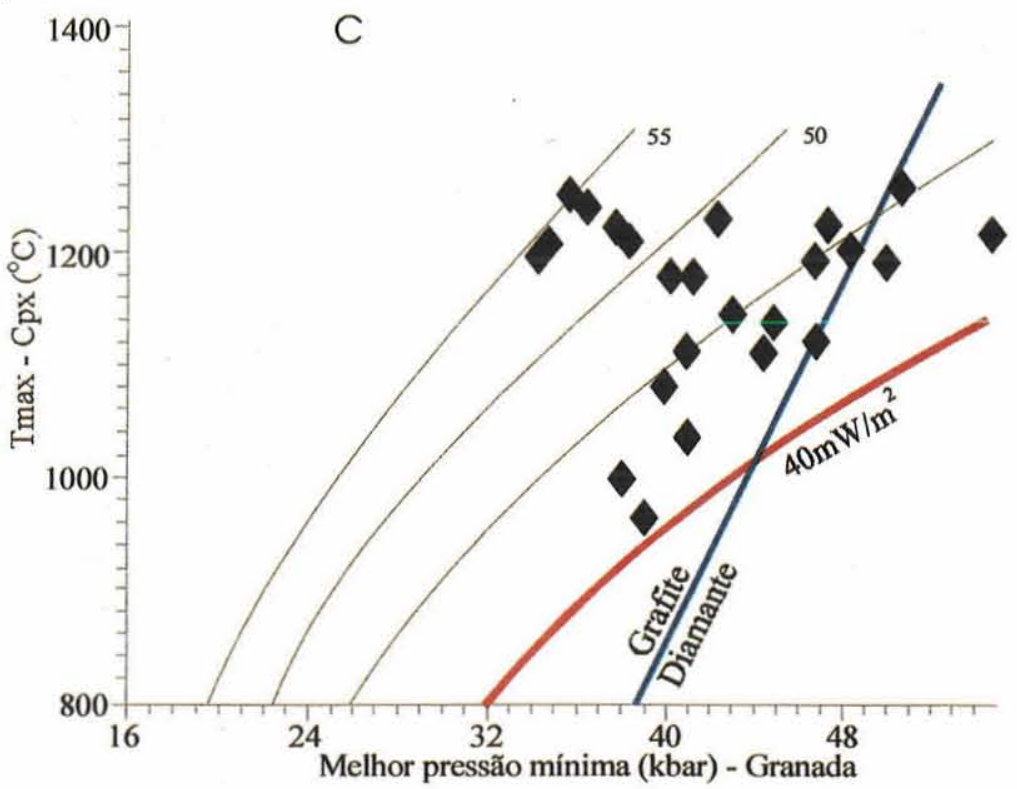

Figura 9-Bloco Serrinha: (A) - Núcleo Arqueano preservado do retrabalhamento durante o Ciclo Transamazônico. (B) - Pressão de granadas das várias províncias kimberlíticas. $(C)$ - Diagrama temperatura máxima de clinopiroxênio $\left({ }^{O} C\right) x$ melhor pressão mínima de granadas (kbar). 
terra está na remoção da vegetação primitiva, nos diferentes tipos e intensidades de culturas, varáveis de pequenas para grandes propriedades.

No Brasil, cerca de duas a três dezenas de kimberlitos foram descobertos pela identificação de anomalias em fotografias aéreas, principalmente em áreas onde as rochas encaixantes produzem solos arenosos e pobres. É importante destacar que, em muitas situações, a área da anomalia é maior que a da intrusão em si. Isto está provavelmente relacionado a fatores tais como a intensidade do sistema de falhas/fraturas que se interceptam muitas vezes na área da intrusão, e a distribuição lateral de solo kimberlítico (mais fértil) que extrapola a feição superficial do corpo. Associadas a outras técnicas, as fotografias aéreas também são usadas em análises estruturais, geomorfológicas e definição de vales e terraços de aluviões diamantíferos.

A partir de 1997, scanners multiespectrais, operando no in- tervalo de comprimentos de ondas de $2000 \mathrm{~nm}$ a $2500 \mathrm{~nm}$ (SWIR), passaram a ser usados na prospecção de kimberlitos. As anomalias são geradas pela detecção (assinatura espectral) da hidroxila $\mathrm{Mg}(\mathrm{OH})$ presente em argilo-minerais típicos da alteração de kimberlitos. $\mathrm{O}$ uso da técnica é restrito às regiões áridas e semi-áridas, com exposições mínimas de solo/rocha em torno de $40 \%$. Levantamentos realizados no Brasil apontaram anomalias sobre kimberlitos conhecidos e também sobre outras rochas anômalas em $\mathrm{MgO}$ (Uren et al. 1999).

O êxito das técnicas exploratórias descritas depende essencialmente da habilidade, treinamento e experiência do cientista, geólogo, técnico, ou prospector em atividade.

CONCLUSÕES Diamantes são preferencialmente encontrados $\mathrm{em}$ regiões onde rochas arqueanas estejam preservadas e repousem sobre litosfera espessa e fria. Os cratons arqueanos

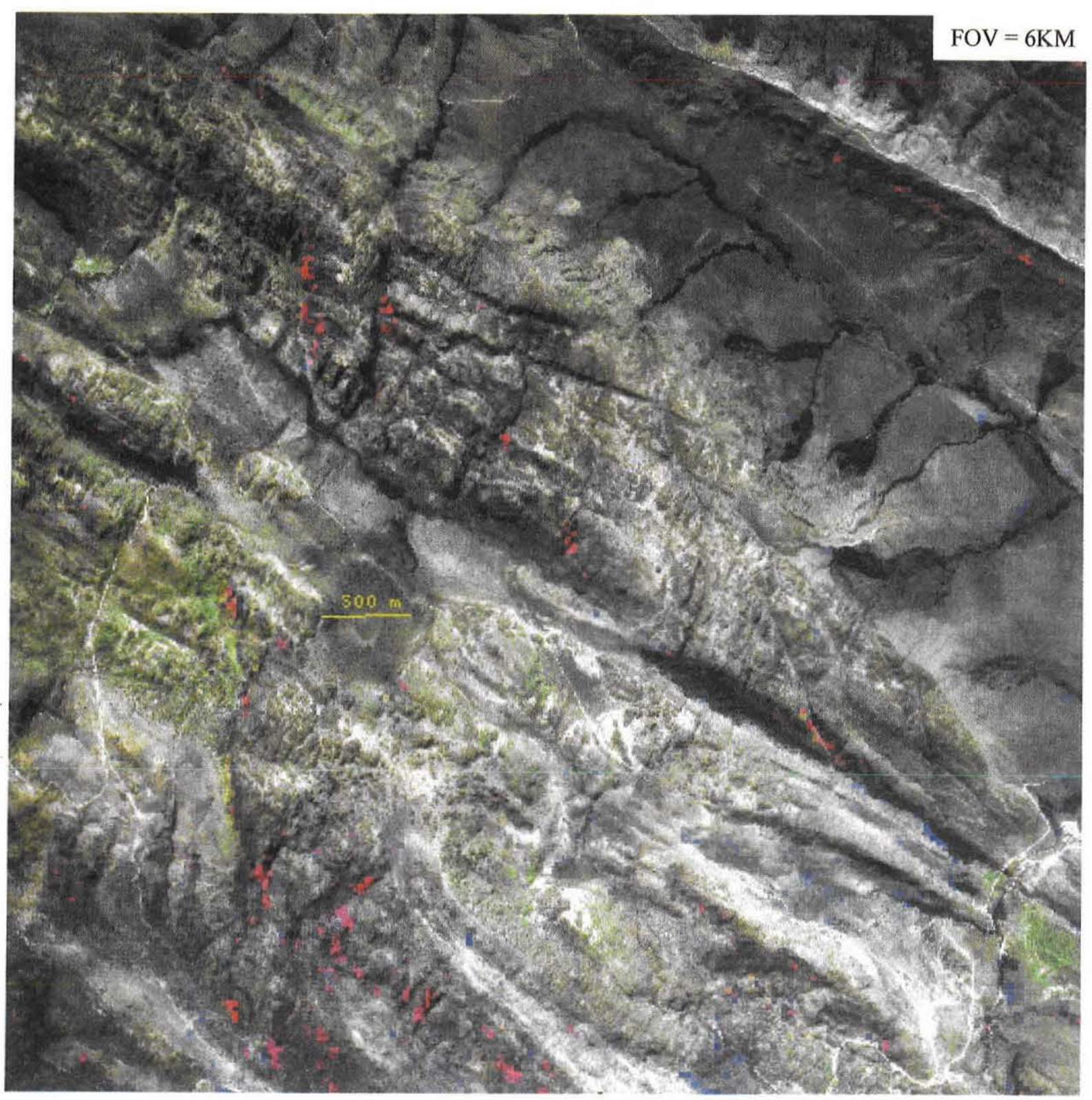

Figura 10 - Feição superficial de kimberlito. Composição: imagem TM bandas 752 + fotografia aérea. Fonte dos dados: De Beers do Brasil. 
constituem portanto os alvos prioritários na prospecção para diamante. Os modelos de exploração de depósitos primários devem incorporar estudos de geotectônica e geofísica que permitam identificar as regiões onde a litosfera sob os cratons arqueanos esteja ou esteve preservada à época das intrusões dos kimberlitos e lamproítos.

Kimberlitos e lamproítos diamantíferos estão ligados a ambientes geotectônicos distintos. Apesar de Argyle constituir a única mina de diamante de classe mundial relacionada a lamproíto, o teor alto de diamante desta intrusão justifica investimentos na prospecção deste tipo de rocha. A ocorrência fora dos núcleos arqueanos e a menor quantidade de minerais indicadores presentes no lamproíto implica no redirecionamento da prospecção tradicional para kimberlito.

A prioridade de um alvo relaciona-se à presença de granada subcálcica, cromita com alto $\mathrm{Cr}$ e populações de granada eclogítica com alto Na. Variações no $\mathrm{Ph}$ do solo (laterização) podem destruir os minerais kimberlíticos próximos à superfícic. Exceto a cromita, os minerais indicadores são destruídos quando a intrusão é submetida a processos metamórficos.

A seleção de anomalias aeromagnéticas em áreas magneticamente agitadas deve associar-se ao exame de fotografias aéreas, levantamentos multiespectrais e coleta de amostras para recuperação de minerais indicadores. A associação de anomalias magnéticas com feeções do terreno observadas em fotografïas aéreas agiliza a identificação da fonte do magnetismo.

Anomalias de vegetação constituem o principal critério na deteç̧ão direta de kimberlitos em fotografias aéreas, a exemplo da experiência adquirida na região de Picos, Piauí, onde a correlação entre pequenos açudes e cultura de subsistência com solos argilosos, mais impermeáveis e férteis resultantes de kimberlitos possibilitou a identificação de várias intrusões em fotografias aéreas.

No Bloco Serrinha, as condições de manto amostradas pelos kimberlitos das diferentes províncias foram estimadas entre $950^{\circ} \mathrm{C}$ e $1200^{\circ} \mathrm{C}$ e pressões entre $34,5 \mathrm{Kbar}$ e $55 \mathrm{Kbar}$. A variação do gradiente geotérmico entre $42 \mathrm{mWm}^{-2}$ e $45 \mathrm{mWm}^{-2}$ amostrada, respectivamente, por kimberlitos da região central do bloco e dos mais próximos as suas bordas, indicam que a espessura da litosfera sob o mesmo foi adelgaçada em cerca de $40 \mathrm{~km}$ junto às margens retrabalhadas durante as orogêneses proterozóicas. Os dados de gradiente geotérmico obtidos em kimberlitos da região central sugerem que um manto depletado, favorável à cristalização de diamante, prevalecia na época das intrusões.

No Brasil, o uso de scanner aerotransportado multiespectral na prospecção de kimberlito se restringe à determinadas áreas na porção norte do Craton do São Francisco. O período mais favorável para levantamento deste tipo é o mês de agosto, quando a presença de nuvens é mínima, a exposição de solo e rocha é máxima e a cobertura vegetal verde está praticamente ausente.

Agradecimentos À De Beers do Brasil pela anuência da publicação de dados referentes a trabalhos internos dos quais o autor participou ao longo de 18 anos e aos revisores da RBG pelas sugestões ao original.

\section{Referências}

Clement C.R. 1982. Comparative geological study of some major kimberlite pipes in the northern Cape and Orange Free State. Unpublished Ph.D. thesis, University of Capetown, South Africa.

Clement C.R. \& Reid A.M. 1989. The origin of kimberlite pipes: an interpretation based on a synthesis of geological features displayed by southern African occurences. In: J. Ross (ed.) Kimberlite and Related Rock. Geological Society of Australia, Special Publication no. 14, p. 632-646.

Clement C.R. Skinner E.M.W. Scott-Smith B.H. 1984. Kimberlite redefined. Journal of Geology; 92:223-228.

Cliford T.N. 1966. Tectono-metallogenic units and metallogenic provinces in Africa. Earth and Planetary Science Letters, 1:421-434.

Condie K.C. 1997. Plate Tectonics and Crustal Evolution. ButterworthHeineman, Fourth Edition, Great Britain.

Dawson J.B. 1980. Kimberlite and their Xenolith. Springer-Verlag. Berlin, 252p.

Edler E. \& Bizzi L.A. 1996. PT Estimate for the Serrinha Block. Bahia: Evidence for Delimitation and Adiabatic Upwelling of Mantle Material in the Proterozoic. Sopemi, Relatório Interno.

Fipke C. Gurney J.J. Moore R. 1995. Diamond Exploration Techniques Emphasising Indicator Mineral Geochemistry and Canadian Examples. Geological Survey of Canada, Bulletin 423.

Gurney J.J. 1984. A correlation between garnets and diamonds in kimberlites. In: J.E. Glover \& P.G. Harris (eds). Kimberlite occurence and origin: a basis for conceptual models in exploration. Geology Department and University Extension, University of Western Australia, Publication no. 8, p. 143-166.

Haggerty S.E. 1986. Diamond genesis in a multiply-constrained model. Nature, 320:34-38

Haggerty S.E. 1992. Diamond in west África: tectonic setting and kimberlite productivity. Russian Geology and Geophisics, 33(10):35-49.

Helmstaed H.H. 1992. Primary diamond deposits: what controls their size, grade and location. Giant Ore Deposits Workshop, Kingston.
Jaques A.L. Lewis J.D. Smith C.B. 1986. The kimberlites and lamproite of Western Australia. Geological Survey of Western Australia, Bulletin 132, $268 p$.

Jordan T.H. 1979. The Deep Structure of the Continents. Sci. Am, 240:92-107.

Kaminsky F.V. Feldman A.A. Varlamov V.A. Boyko A.N. Olofinsky L.N. Shofman I.L. Vaganov V.I. 1995. Prognostication of primary diamond deposit. Journal of Geochemical Exploration 53:167-182.

Lee C.T. Yin Q. Rudnick R.L. Jacobsen S.B. 2001. Preservation of ancient and fertile lithosphere mantle beneath the southwestern United State. Nature, V. 441, 3 May.

Mitchell R.H. 1989. Aspects of the petrology of kimberlite and lamproite: some definition and distinction. In Kimberlites and Related Rocks, J. Ross (ed.), Geological Society of Australia, Special Publication, 14, p.7-45.

Nyblade A.A. 2001. Hard - cored continents. Nature, 411, 3 May.

O'Reilly S.Y. \& Griffin W.L. 1996.4 - D Lithosphere Mapping: methodology and examples. Tectonophisics 262:3-18.

Pereira R.S. Zang M. Bizzi L. 1996. Target selection in the Bahia Project Area using regional scale geophisics, remote sensing and geochemistry Geophisical Services Division, Sopemi, Brasília.

Ringwood A.E. Kesson S.E. Hibberson W., Ware N. 1992. Origin of kimberlite and related magmas. Earth and Planetary Science Letter, 113: 521-538.

Scott-Smith B.H. 1992. Contrasting Kimberlites and Lamproites. Exploration Mining Geology, 1:371-381.

Uren E. Pereira R.S. Richards D.A. Spooner C.N. 1999. Airborne Multispectral Scanner: report on first pass interpretation of the Bahia Survey, Brazil. Remote Sensing Unit, Geoscience Center, De Beers, Jahannesburg.

Manuscrito A-1190

Recebido em 19 de novembro de 2000 Revisão do autor em 15 de setembro de 2001 Revisão accita em 30 de setembro de 2001 